\title{
Serum free light chains: diagnostic and prognostic value in multiple myeloma
}

\author{
Pavai Sthaneshwar*, Veerasekaran Nadarajan, \\ Jayaranee A.S. Maniam, Nani Nordin and \\ Gan Gin Gin \\ Department of Pathology, University of Malaya, \\ Kuala Lumpur, Malaya
}

\begin{abstract}
Background: Measurement of serum free light chains (FLCs) has recently become available for the diagnosis and monitoring of patients with plasma cell dyscrasias. The aim of this study was to investigate the performance of the serum FLC assay as a tumour marker by comparing FLC concentrations with serum protein electrophoresis (PE) results in the diagnosis of multiple myeloma (MM). In addition, we also evaluated the prognostic value of the baseline serum FLC ratio in patients with MM.
\end{abstract}

Methods: We measured FLC concentrations and calculated the kappa/lambda ( $/ \lambda$ ) FLC ratios for three groups (control, polyclonal gammopathy and MM).

Results: The FLC ratio at a cut-off threshold of 2.0 showed higher sensitivity and specificity compared with serum electrophoresis for the diagnosis of MM. We used the median FLC ratio of $>57.5$ and $<0.04$ for $\kappa$ and $\lambda$ secretors, respectively, for assessing survival. Survival was 30 months in patients with the $\kappa / \lambda$ ratio of $>57.5$ and $<0.04$ compared to 47 months in patients with the ratio $<57.5$ and $>0.04$, indicating that more abnormal serum FLC ratios are associated with poorer survival ( $p<0.011)$.

Conclusions: Despite the limitations of the assay, the results of our study indicate that the FLC assay in combination with serum PE has an increased sensitivity in the diagnosis of MM. Also, baseline measurement of the $\kappa / \lambda$ ratio provides prognostic information in these same patients.

Clin Chem Lab Med 2009;47:1101-7.

Keywords: $\beta_{2}$-microglobulin; multiple myeloma; serum electrophoresis; serum free light chains.

\section{Introduction}

Monoclonal gammopathies are a group of disorders characterised by clonal expansion of $\mathrm{B}$ cells that usually secrete intact monoclonal immuoglobulins, monoclonal free light chains (FLCs) or both. They may

*Corresponding author: Pavai Sthaneshwar, Department of Pathology, University of Malaya, 50603 Kuala Lumpur,

Malaya

E-mail: pavai@um.edu.my

Received May 2, 2009; accepted June 26, 2009 be present as a spectrum of diseases that include multiple myeloma (MM), Waldenstrom's macroglobulinaemia, asymptomatic myeloma, non-secretory myeloma, AL-amyloidosis, light chain deposition disease and monoclonal gammopathy of undetermined significance (MGUS) (1). Until recently, the recommended laboratory algorithm for patients suspected of having $M M$, primary amyloid $(A L)$, and related disorders included serum or urine protein electrophoresis (PE) and immunofixation electrophoresis (IFE) to optimise detection of monoclonal gammopathies (2). Quantitation of monoclonal protein (M-protein) by PE is recommended as a tumour marker in patients with monoclonal gammopathy $(3,4)$. However, PE is a semiquantitative method for detection of $\mathrm{M}$ proteins, and may be misinterpreted as a negative result due to lack of sensitivity, or the masking effect from other proteins when the M-protein is not present in the $\gamma$ fraction. The accuracy of urine PE has been questioned in patients with proteinuria (5). Moreover, PE and IFE have limited use in the identification of patients with light chain MM (LCMM), non-secretory $M M$ and $A L$ amyloidosis where the M-protein may not be present in sufficient concentrations for detection.

In order to diagnose and monitor these patients, an alternative assay has been developed to identify, characterise and quantitate serum FLCs. The only commercially available quantitative assay for FLCs was introduced in 2001 (FREELITE ${ }^{\mathrm{T}}$, The Binding Site Ltd, Birmingham, UK). This immunoassay measures very low concentrations of FLC in serum, with virtually no cross reactivity with light chains contained within intact immunoglobulins (6). This assay is not capable of distinguishing monoclonal from polyclonal FLCs, but the use of the kappa to lambda $(\kappa / \lambda)$ ratio enables the identification of imbalances in light chain production. Abnormal $\kappa$ and $\lambda$ FLC ratios may be due to immune suppression, immune stimulation, reduced renal clearance or monoclonal lymphoplasmacytic proliferative disorders. Sera from patients with either polyclonal hypergammaglobulinaemia or renal impairment often have increased $\kappa$ FLC and $\lambda$ FLC, but in these cases the $\kappa / \lambda$ FLC ratio remains normal. It is presumed that abnormal $\kappa / \lambda$ FLC ratios only result from a clonal B-lymphoid or plasma cell proliferative disorder, and is interpreted as evidence of free monoclonal light chains in the serum. Recently, Snozek et al. (7) have described that the concentration of serum FLCs at initial diagnosis is an important predictor of prognosis in myeloma, and can be incorporated into International Staging System (ISS) for improved risk stratification.

The goal of this study was to investigate the performance of the serum FLC assay as a tumour marker by comparing FLC concentrations with serum PE for 
the diagnosis of MM. In addition, we also evaluated the prognostic value of baseline serum FLC ratios in these same patients.

\section{Patients and methods}

The study group comprised 59 patients who had been diagnosed with MM from 1999 to 2008, and 30 patients who were noted to have polyclonal gammopathy due either to infection or inflammation. Archived serum samples from blood collected at the time of initial diagnosis were available for measurement of serum FLCs. The reference interval for serum FLC was established using 30 blood samples collected from healthy blood donors. The clinical diagnosis of MM was based on findings of serum or urine PE and IFE, plasma cell content of bone marrow aspirates or trephine biopsies, together with the clinical features of MM, including lytic bone lesions or fractures. Information regarding patient demographics, clinical presentations and indicators of disease activity, such as serum calcium, serum albumin, haemoglobin, platelet count, M-protein concentrations, plasma cell infiltration, $\mathrm{C}$-reactive protein (CRP) concentrations, serum $\beta_{2}$-microglobulin $(\beta 2 \mathrm{M})$ and presence of bony lytic lesions recorded at the time of diagnosis, were retrieved from the medical records and the laboratory information system. Serum FLC concentrations were measured using a latex-enhanced immunonephelometry method (The Binding Site, Birmingham, UK) performed using the Beckman Coulter IMMAGE ${ }^{\circledR} 800$ analyser (Beckman Coulter, Brea, CA, USA).

\section{Statistical analysis}

Means, standard deviations (SDs) and reference intervals (mean $\pm 2 \mathrm{SD}$ ) were calculated for $\kappa, \lambda$ and the $\kappa / \lambda$ ratio. One-way ANOVA was used to compare the mean $\kappa / \lambda$ ratio in normal, polyclonal and MM patients.

Sensitivity, specificity, positive predictive value (PPV) and negative predictive value (NPV) were calculated for the $\kappa / \lambda$ ratio using different cut-off thresholds and for the results of serum PE (Table 1).

Survival was defined as the time from initial diagnosis to death or the last follow-up and was calculated by the method of Kaplan and Meier (8). The survival curves were compared using the log-rank test. The Cox proportional hazards regression model was used to analyse univariately the influence of prognostic factors on survival. Statistically significant factors were further tested in multivariate analysis with stepwise forward selection. $p$-Values $<0.05$ were considered to be significant. The relationship between abnormal $\kappa / \lambda$ ratio and the other disease related parameters was assessed using the $\chi^{2}$ test. Statistical analysis was performed using SPSS for Windows version 11.0 (SPSS Inc., Chicago, IL, USA).

\section{Results}

The reference range for the serum $\kappa, \lambda$ and $\kappa / \lambda$ ratio calculated from 30 healthy donors was found to be $4.42-17.7,7.63-18.23$ and $0.50-1.20 \mathrm{mg} / \mathrm{L}$, respectively (mean $\pm 2 \mathrm{SD}$ ). The reference intervals recommended by the manufacturer for $\kappa$ and $\lambda$ when using this platform are 3.3-19.4 $\mathrm{mg} / \mathrm{L}$ and $5.7-26.3 \mathrm{mg} / \mathrm{L}$, respectively. The mean (median) serum $\kappa, \lambda$ and $\kappa / \lambda$ ratio in the group with polyclonal gammopathy were 69.47 (52.8), $86.85(54.1)$ and $0.89(0.81) \mathrm{mg} / \mathrm{L}$, respectively. The mean $\kappa$ and $\lambda$ values were significantly increased compared to the controls $(p<0.05)$, but no significant difference was noted in the $\kappa / \lambda$ ratio $(p=0.73)$ between controls and patients with polyclonal gammopathy.

Fifty-three patients with MM (90\%) had intact immunoglobulin MM (IIMM). Based on IFE results, 44 $(83 \%)$ of them were identified to have the $\lg G$ isotype, eight (15\%) with IgA and one (2\%) with IgM. $\kappa$ Light chain restriction was observed in $30(57 \%)$ patients and $\lambda$ light chain restriction in 23 (43\%). The remaining six patients were diagnosed as light chain MM (LCMM). Three of the six LCMM patients $(10 \%)$ were noted to be $\kappa$ secretors, and the other three were $\lambda$ secretors. The mean (median) $\kappa, \lambda$ concentrations in 59 patients with MM were 819.98 (140.75) $\mathrm{mg} / \mathrm{L}$ and 841.85 (14.3) mg/L, respectively. These values were significantly increased when compared to those in the control group; $p=0.003,0.035$. The mean (median) $\kappa / \lambda$ ratio for $\kappa$ secretors and $\lambda$ secretors were 135.9 (57.5) and 0.24 (0.04), respectively. The $\kappa / \lambda$ ratio in MM was significantly abnormal compared to that of controls $(p=0.005)$, and the group with polyclonal gammopathy $(p=0.008)$. The distributions of $\kappa$ and $\lambda$ FLC in the control group, polyclonal group and patients with $\mathrm{MM}$ are shown in the scatter plot (Figure 1). The distribution of the $\kappa / \lambda$ ratio in the control group, polyclonal gammopathy group, and $\kappa-\mathrm{MM}$ and $\lambda$-MM groups are shown in the box plot (Figure 2). Fourteen of the patients with MM succumbed to their disease. In nine patients, there was no follow-up after a period of time.

Of the 59 patients with MM, 57 had increased serum FLC concentrations and abnormal $\kappa / \lambda$ ratios according to the type of light chain restrictions. Two patients had a normal $\kappa / \lambda$ ratio and both of these patients had $\operatorname{lgG}-\lambda$ MM. In one of them, serum $\kappa$ and $\lambda$ concentrations were normal, the other patient showed $\kappa$ and $\lambda$ concentrations that were increased, accounting for the normal $\kappa / \lambda$ ratio. In the patients with polyclonal gammopathy, higher serum FLC concentrations were observed. However, the $\kappa / \lambda$ ratio was within the val-

Table 1 Sensitivity, specificity, PPV and NPV of the $\kappa / \lambda$ ratio at different cut-off thresholds, and serum protein electrophoresis.

\begin{tabular}{llccc}
\hline Method (cut-off value) & Sensitivity, $\%$ & Specificity, $\%$ & PPV, $\%$ & NPV, $\%$ \\
\hline$\kappa / \lambda(0.5-1.2)$ & 96.6 & 93.0 & 93.4 & 96.5 \\
$\kappa / \lambda(0.26-1.65)$ & 96.6 & 96.6 & 96.6 & 96.6 \\
$\kappa / \lambda(0.5-2.0)$ & 96.6 & 100 & 100 & 96.8 \\
Serum PE & 86.4 & 100 & 100 & 88.2 \\
\hline
\end{tabular}

PPV, positive predictive value; NPV, negative predictive value; serum PE, serum protein electrophoresis. 


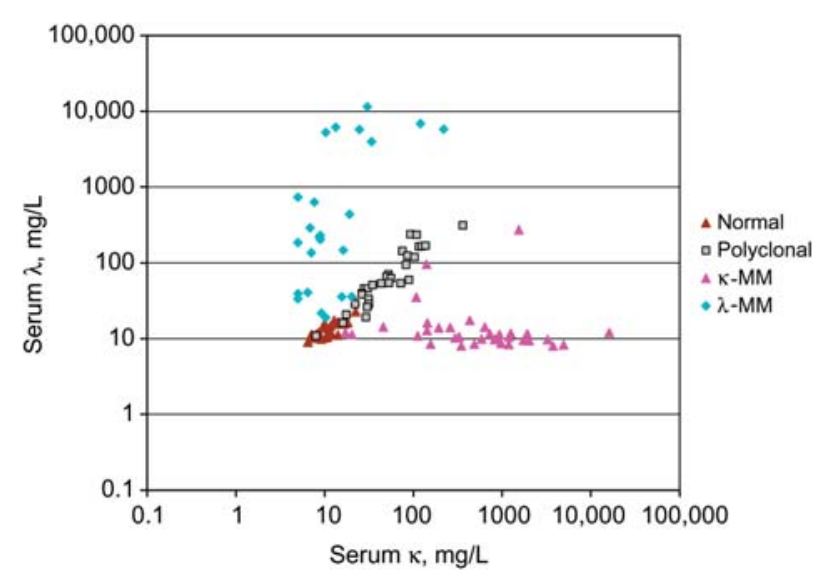

Figure 1 Distributions of $\kappa$ and $\lambda$ FLC in normal, multiple myeloma and polyclonal gammopathy group.

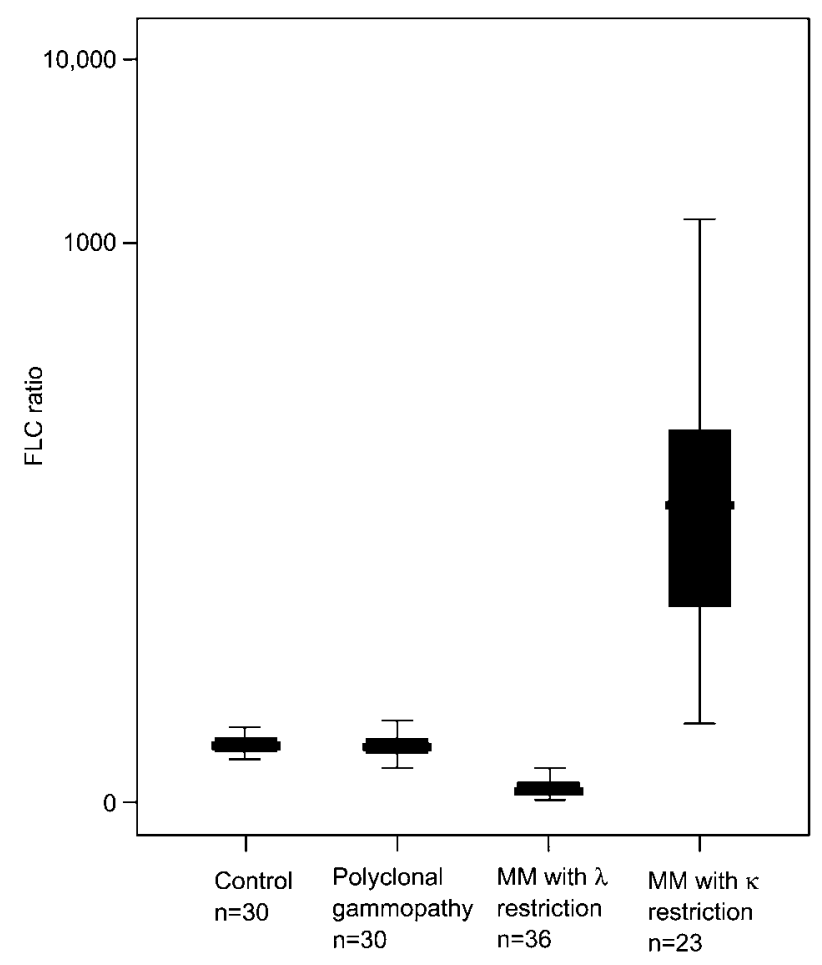

Figure 2 Distribution of $\kappa / \lambda$ ratio in control, polyclonal gammoapthy, multiple myeloma with $\kappa$ - and $\lambda$ restriction.

ues obtained for our reference population in all except four in whom the $\kappa / \lambda$ ratio was slightly increased $(\kappa / \lambda$ ratio $>1.2$ and $<2$ ). When a cut-off threshold for the $\kappa / \lambda$ ratio of 2.0 was used, it showed better sensitivity, specificity, PPV and NPV (Table 1) when compared with the reference value for the $\kappa / \lambda$ ratio of $0.2-1.65$, and when compared with serum PE.

In eight patients with $\mathrm{MM}$, the M-protein was not detected in the $\gamma$ region by serum PE. However, the PE showed abnormally elevated $\beta$ and $\alpha 2$ globulins in three and one patient, respectively. These four patients were diagnosed with intact IgA MM by serum IFE. The other four patients had LCMM. In two of these patients, serum PE showed no abnormalities, whereas the other two were noted to have hypogammaglobulinaemia. However, the M-protein was iden- tified in PE and IFE of urine. All eight patients had increased serum FLC concentrations and an abnormal $\kappa / \lambda$ ratio.

\section{Survival analysis and prognostic significance of serum FLC and other variables}

The median survival time for the patients with MM patients was noted to be 43 months. Univariate analysis of the parameters using Cox proportional hazards regression showed that six out of the ten variables analysed were associated significantly with survival. These variables included albumin, calcium, creatinine, the serum FLC ratio, ISS, and $\beta 2 \mathrm{M}$ (Table 2 and Figure 3). A median FLC ratio $>57.5$ and $<0.04$ for $\kappa$ and $\lambda$ secretors, respectively, was used for assessing prognosis. In the multivariate analysis, the serum FLC ratio ( $\kappa / \lambda$ and $\lambda / \kappa$ ratio), serum $\beta 2 M$ and serum calcium concentrations were found to have independent prognostic predictive value for survival. p-Values were $0.011,0.006$ and 0.022 , respectively.

\section{Correlations with parameters of disease activity (Table 3)}

The FLC ratio correlated with creatinine, haemoglobin, calcium, $\beta 2 \mathrm{M}$, Durie-Salmon staging (DSS) and ISS $(p<0.05)$. No correlation was noted with age, gender, and albumin ( $p>0.05)$.

\section{Discussion}

Serum PE is the most common test in use for detecting monoclonal immunoglobulins, with a sensitivity that is between $500 \mathrm{mg} / \mathrm{L}$ and $2000 \mathrm{mg} / \mathrm{L}$ (9). The wide range of sensitivity can be explained by the different migration patterns of M-proteins. In the majority of cases, the monoclonal component migrates in the $\gamma$ globulin region and is easier to detect. However, occasionally the M-spike can be missed if it is masked by proteins within the $\beta$ and $\alpha$ globulin region. Immunofixation is a more sensitive technique and can detect between $100 \mathrm{mg} / \mathrm{L}$ and $150 \mathrm{mg} / \mathrm{L}$ of M-protein (6). A new commercially available automated immunoassay enables quantifitation of serum $\kappa$ and $\lambda$ FLCs. The ability of the FLC assay to identify most patients with LCMM suggests that analysis of urine may rarely be needed for diagnosis of these patients (3). The serum FLC assay has also been shown to be useful for the diagnosis and monitoring of patients with non-secretory myeloma (10). In our study, 96.6\% (57/ 59) of patients with MM had increased serum FLC concentrations and an abnormal $\kappa / \lambda$ ratio. The light chains were increased according to the clonal type. In two patients, the serum FLC ratio was within the reference interval, although serum PE showed the presence of M-protein. It has been reported that in $10 \%$ of IIMM, the $\kappa / \lambda$ ratio can be normal $(11,12)$. However, in our study, serum PE was not helpful in diagnosing $\mathrm{MM}$ in eight patients $(10 \%)$, and the M-protein was detected either by IFE or urine PE. Four of these patients had an M-band migrating within the $\beta$ or $\alpha_{2}$ 
Table 2 Cox model and univariate analysis of patients with multiple myeloma.

\begin{tabular}{|c|c|c|c|}
\hline Parameters & $\begin{array}{l}\text { Median survival } \\
\text { rate, months }\end{array}$ & Number, $\mathrm{n}$ & p-Value \\
\hline \multicolumn{4}{|l|}{ Age, years } \\
\hline$<65$ & 46 & 34 & \multirow[t]{2}{*}{0.22} \\
\hline$>65$ & 42 & 25 & \\
\hline \multicolumn{4}{|l|}{ Sex } \\
\hline Male & 47 & 28 & \multirow[t]{2}{*}{0.69} \\
\hline Female & 42 & 31 & \\
\hline \multicolumn{4}{|l|}{$\mathrm{Hb}, \mathrm{g} / \mathrm{L}$} \\
\hline$\geq 100$ & 43 & 29 & \multirow[t]{2}{*}{0.38} \\
\hline$<100$ & 35 & 30 & \\
\hline \multicolumn{4}{|l|}{ Serum FLC ratio } \\
\hline$<57.5$ or $>0.04$ & 47 & 28 & \multirow[t]{2}{*}{0.04} \\
\hline$>57.5$ or $<0.04$ & 30 & 31 & \\
\hline \multicolumn{4}{|l|}{ Calcium, mmol/L } \\
\hline$<2.5$ & 47 & 36 & \multirow[t]{2}{*}{0.002} \\
\hline$\geq 2.5$ & 20 & 23 & \\
\hline \multicolumn{4}{|c|}{ Measured albumin, g/L } \\
\hline$<35$ & 35 & 42 & \multirow[t]{2}{*}{0.02} \\
\hline$\geq 35$ & 72 & 17 & \\
\hline \multicolumn{4}{|l|}{ Creatinine, $\mu \mathrm{mol} / \mathrm{L}$} \\
\hline$\geq 115$ & 22 & 38 & \multirow[t]{2}{*}{0.045} \\
\hline$<115$ & 43 & 21 & \\
\hline \multicolumn{4}{|l|}{$\beta 2 \mathrm{M}, \mathrm{mg} / \mathrm{L}$} \\
\hline$<5.5$ & 47 & 36 & \multirow[t]{2}{*}{0.013} \\
\hline$>5.5$ & 30 & 23 & \\
\hline \multicolumn{4}{|l|}{ DS staging } \\
\hline $1 \mathrm{~A}$ & 42 & 13 & \multirow[t]{5}{*}{0.168} \\
\hline $2 \mathrm{~A}$ & 35 & 3 & \\
\hline $2 \mathrm{~B}$ & 6 & 2 & \\
\hline $3 \mathrm{~A}$ & 57 & 31 & \\
\hline $3 B$ & 22 & 10 & \\
\hline \multicolumn{4}{|l|}{ IS staging } \\
\hline 1 & No event & 5 & \multirow[t]{3}{*}{0.045} \\
\hline 2 & 42 & 31 & \\
\hline 3 & 30 & 23 & \\
\hline
\end{tabular}

$\mathrm{Hb}$, haemoglobin; FLC, free light chain; $\beta 2 \mathrm{M}, \beta_{2}$-microglobulin; DS, Durie-Salmon; IS, International Staging.

region, and the remaining four patients had LCMM. In all these patients, the $\kappa / \lambda$ ratio was abnormal. Serum FLC assays are more sensitive than PE in conditions, such as LCMM and MM, where the M-spike can be masked by other proteins.

Increased concentration of FLC can occur not only in $\mathrm{MM}$, but also in inflammation or infection where there is an increased synthesis (4). In addition, patients with renal impairment can retain FLCs for a longer time $(6,13)$. We noted increased serum FLC concentrations in patients with polyclonal gammo-

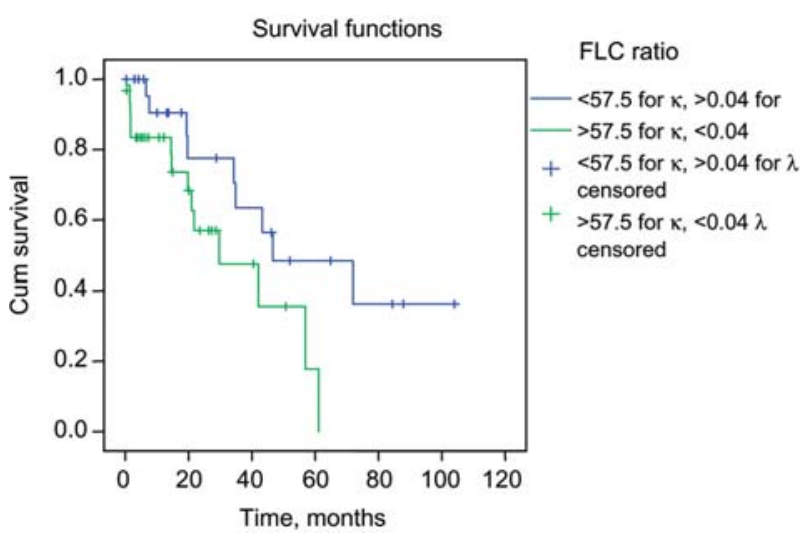

Figure 3 Survival functions. pathy, but their $\kappa / \lambda$ ratios were usually normal. In three patients, the ratio was slightly increased but $<2.0$. Abadie et al. (14) observed a mildly increased $\kappa / \lambda$ ratio up to 3.1 with increased serum creatinine and/or polyclonal hypergammaglobulinaemia. Hence, they recommended a suitable reference interval to be used in interpreting results in these patients. Using a cut-off threshold of 2.0 for the FLC ratio, 100\% PPV and $96.8 \%$ NPV was noted, enabling us to differentiate polyclonal gammopathy from MM. Similar findings have been reported by Kang et al. (15). The present study shows higher sensitivity when a cut-off threshold of 2.0 for the $\kappa / \lambda$ ratio was used, compared to serum $\mathrm{PE}(96.6 \%$ vs. $86.4 \%)$ in detecting $\mathrm{MM}$. This finding is in agreement with that of other studies (15, 16). The sensitivity was $100 \%$ when both assays were used. Therefore, if a diagnosis of MM is suspected, optimum laboratory practice should be to screen sera using both electrophoresis and the FLC assay.

The outcome for patients with $\mathrm{MM}$ is highly variable. With the use of conventional chemotherapy, the median survival of patients with MM has been $\sim 3$ years, and the proportion of long-term survivors is disappointingly small. Since the first formal publication 40 years ago by Carbone et al. (17), several prognostic factors that identify groups of patients with significantly different survival probabilities have 
Table 3 Comparison of patient demographics according to baseline FLC ratios.

\begin{tabular}{|c|c|c|c|}
\hline Parameters & $\begin{array}{l}\text { FLC ratio } \\
<57.5 \text { or }>0.04 \\
(n=28)\end{array}$ & $\begin{array}{l}\text { FLC ratio } \\
>57.5 \text { or }<0.04 \\
(n=31)\end{array}$ & $\begin{array}{l}\mathrm{p} \text {-Value } \\
\chi^{2}\end{array}$ \\
\hline \multicolumn{4}{|l|}{ Age, years } \\
\hline$<65$ & 15 & 19 & \multirow[t]{2}{*}{$>0.05$} \\
\hline$>65$ & 13 & 12 & \\
\hline \multicolumn{4}{|l|}{ Sex } \\
\hline Male & 15 & 13 & \multirow[t]{2}{*}{$>0.05$} \\
\hline Female & 13 & 18 & \\
\hline \multicolumn{4}{|l|}{$\mathrm{Hb}, \mathrm{g} / \mathrm{L}$} \\
\hline$\geq 100$ & 21 & 8 & \multirow[t]{2}{*}{$<0.0001$} \\
\hline$<100$ & 7 & 23 & \\
\hline \multicolumn{4}{|c|}{ Calcium, mmol/L } \\
\hline$<2.5$ & 21 & 15 & \multirow[t]{2}{*}{$<0.05$} \\
\hline$\geq 2.5$ & 7 & 16 & \\
\hline \multicolumn{4}{|c|}{ Measured albumin, g/L } \\
\hline$<35$ & 18 & 7 & \multirow[t]{2}{*}{$>0.05$} \\
\hline$\geq 35$ & 10 & 24 & \\
\hline \multicolumn{4}{|c|}{ Creatinine, $\mu \mathrm{mol} / \mathrm{L}$} \\
\hline$<115$ & 23 & 15 & \multirow[t]{2}{*}{$<0.001$} \\
\hline$\geq 115$ & 5 & 16 & \\
\hline \multicolumn{4}{|l|}{$\beta 2 \mathrm{M}, \mathrm{mg} / \mathrm{L}$} \\
\hline$<5.5$ & 22 & 14 & \multirow[t]{2}{*}{$<0.001$} \\
\hline$\geq 5.5$ & 6 & 17 & \\
\hline \multicolumn{4}{|l|}{ DS staging } \\
\hline 1 and 2 & 12 & 6 & \\
\hline 3 & 16 & 25 & $<0.05$ \\
\hline \multicolumn{4}{|l|}{ IS staging } \\
\hline 1 and 2 & 22 & 14 & \multirow[t]{2}{*}{$<0.01$} \\
\hline 3 & 6 & 17 & \\
\hline
\end{tabular}

$\mathrm{Hb}$, hemoglobin; FLC, free light chain; $\beta 2 \mathrm{M}, \beta_{2}$-microglobulin; DS, Durie-Salmon; IS, International Staging.

been identified. In 1975, the DSS system (18) was introduced and is still widely used. In the 1980s, $\beta 2 \mathrm{M}$ emerged as a simple reliable predictor of survival. Subsequently, other prognostic factors were introduced, including serum CRP, albumin, the plasma cell labelling index, cell cycle analysis, creatinine clearance and deletion of chromosome $13(19,20)$. In our study, univariantly significant baseline factors associated with decreased survival were albumin $<35$ $\mathrm{g} / \mathrm{L}$, calcium $\geq 2.5 \mathrm{mmol} / \mathrm{L}$, creatinine $\geq 115 \mu \mathrm{mol} / \mathrm{L}$, a serum FLC ratio $>57.5$ and $<0.04$, higher International Staging, and $\beta 2 \mathrm{M}>5.5 \mathrm{mg} / \mathrm{L}$ (Table 2). Among these baseline variables, the serum FLC ratio, serum $\beta 2 \mathrm{M}$ and serum calcium retained independent prognostic significance.

Several biochemical markers are linked to disease activity, and the most important of them is $\beta 2 \mathrm{M}$ concentrations. $\beta 2 \mathrm{M}$ is part of the major histocompatibility complex class I molecule on the cell surface of nucleated cells, and is regarded as the most important prognostic factor in MM. The ISS uses serum $\beta 2 \mathrm{M}$ concentrations for staging of $\mathrm{MM}$. $\beta 2 \mathrm{M}$ concentrations increase as a result of both tumour burden and deterioration of renal function. Several threshold values for $\beta 2 \mathrm{M}(3-6 \mathrm{mg} / \mathrm{dL}$ ) have been used to discriminate prognostic subgroups $(21,22)$. We used a cut-off threshold of $5.5 \mathrm{mg} / \mathrm{dL}$. The higher the $\beta 2 \mathrm{M}$ value, the shorter the survival $(21,22)$.

The DSS system categorises patients into 1 of 3 categories (stage I, II, or III) based on haemoglobin concentrations, serum calcium concentrations, the production rate of M-protein, and the number of osteolytic lesions. Hypercalcaemia remains the most frequent metabolic complication in patients with myeloma, and excessive osteolysis plays a major contributory role in its pathogenesis. In the study by Abildgaard et al. (23), serum calcium showed the highest prognostic significance using multivariate analysis. Higher serum calcium concentrations were also associated with poorer outcome of patients in our study, and multivariate analysis showed calcium to be an independent prognostic factor $(p<0.02)$. Abnormal baseline FLC ratios correlated with creatinine, calcium, DSS, $\beta 2 \mathrm{M}$ and ISS staging, indicating more aggressive disease and higher tumour burden. Similar findings have been reported by van Rhee et al. (24).

Recently, Kyrtsonis et al. (25) described the use of serum FLC concentrations for predicting prognosis, independently of the ISS, in a relatively small group of patients with MM. A study by van Rhee et al. (24) in the same year confirmed that the baseline FLC ratio was predictive of survival within the first 2 years following diagnosis. Snozek et al. (7) suggested that the serum FLC ratio at initial diagnosis is an important predictor of prognosis in myeloma, and can be incorporated into the ISS for improved risk stratification. In their study, they observed that median survival was lower in patients with FLC ratios of $<0.03$ and $>32$. We used the median FLC ratio of $>57.5$ and $<0.04$ for $\kappa$ and $\lambda$ secretors, respectively, for assessing survival. The median FLC ratio used in the study is different from that reported by Snozek et al. (7), possibly due to the smaller number of MM patients in our 
study; 23 (39\%) of which were in stage 3. The different value used could also be attributed to different analysers used in the studies. According to Tate et al. (13), discordant results arising from instruments include differences in the analyser performance, or analytical imprecision on the calculation of the FLC ratio. The survival was 30 months in patients with the $\kappa / \lambda$ ratio of $>57.5$ and $<0.04$, compared to 47 months in patients with the ratio $<57.5$ and $>0.04$. This indicates that higher serum FLC ratios are associated with poorer survival $(p<0.011)$. Our study also supports the findings of previous investigators who found that the serum FLC ratio is an independent prognostic variable in $\mathrm{MM}$. In their recent guidelines for serum-FLC analysis in MM and related disorders, the International Myeloma Working Group (26) has recommended three major indications for the FLC measurement. First, in the context of screening, the serum FLC assay in combination with serum PE and immunofixation yields high sensitivity. Second, the baseline FLC measurement is of major prognostic value in virtually every plasma cell disorder (PCD). Third, the FLC assay allows for quantitative monitoring of patients with oligosecretory PCD.

FLC assays do have some drawbacks. No international standard exists for FLCs. Serum FLC concentrations, by themselves cannot be used to diagnose MM. There is a need for complementary IFE to be performed to confirm the clonality. The FLC ratio can also be normal in IIMM. Tate et al. (13) reported that the inaccuracies in the assay could be attributable to (i) differences in the immunoreactivity of monoclonal FLCs compared to the polyclonal calibrator used for calibration and (ii) over or under estimation of FLC due to polymerisation of monoclonal FLCs. Also, they have reported that the analytical performance and FLC values differed between instruments and methodologies. Despite these limitations, the results of our study indicate that the FLC assay in combination with serum PE has an increased sensitivity in the diagnosis of $\mathrm{MM}$, and baseline measurement of the $\kappa / \lambda$ ratio provides prognostic information in these patients.

\section{Acknowledgements}

We thank Alex Legg (Binding Site) for the guidance during the study.

\section{References}

1. Merlini G. Monoclonal gammopathies. Cancer J 1995;8: $173-80$.

2. International Myeloma Working Group. Criteria for the classification of monoclonal gammopathies, multiple myeloma and related disorders: a report or the International Myeloma Working Group. Br J Haematol 2003;121: 749-57.

3. Bradwell AR, Car-Smith HD, Mead GP, Harvey TC, Drayson MT. Serum test for assessment of patients with Bence Jones myeloma. Lancet 2003;361:489-91.

4. Katzmann JA, Clark RJ, Abraham RS, Bryant S, Lymp JF, Bradwell $A R$, et al. Serum reference intervals and diag- nostic ranges for free kappa and free lambda immunoglobulin light chains: relative sensitivity for detection of monoclonal light chains. Clin Chem 2002;48:1437-44.

5. Le Bricon T, Bengoufa D, Benlakehal M, Bousquet B, Erlich D. Urinary free light chain analysis by the Freelite immunoassay: a preliminary study in multiple myeloma. Clin Biochem 2002;35:565-7.

6. Bradwell AR, Carr-Smith HD, Mead GP, Tang LX, Showell PJ, Drayson MT, et al. Highly sensitive automated immunoassay for immunoglobulin free light chains in serum and urine. Clin Chem 2001;47:673-80.

7. Snozek CL, Katzmann JA, Kyle RA, Dispenzieri A, Larson DR, Therneau TM, et al. Prognostic value of the serum free light chain ratio in newly diagnosed myeloma: proposed incorporation into the international staging system. Leukaemia 2008;22:1933-7.

8. Kaplan E, Meier P. Nonparametric estimation from incomplete observation. J Am Stat Assoc 1958;58:45781.

9. Wolff F, Thiry C, Willems D. Assessment of the analytical performance and the sensitivity of serum free light chains immunoassay in patients with monoclonal gammopathy. Clin Biochem 2007;40:351-4.

10. Drayson M, Tang LX, Drew R, Mead GP, Carr-Smith H, Bradwell AR. Serum free light chain measurements for identifying and monitoring patients with non-secretory multiple myeloma. Blood 2001;97:2900-2.

11. Bratt G. The evolving use of serum free light chain assays in haematology. Br J Haematol 2008;141:413-22.

12. Mead GP, Carr-Smith HD, Drayson MT, Morgan GJ, Child JA, Bradwell AR. Serum free light chains for monitoring multiple myeloma. Br J Haematol 2004;126:34854.

13. Tate JR, Gill D, Cobcroft R, Hickman PE. Practical considerations for the measurement of free light chains in serum. Clin Chem 2003;49:1252-7.

14. Abadie JM, van Hoeven KH, Wells JM. Are renal reference intervals required when screening for plasma cell disorders with serum free light chains and serum protein electrophoresis? Am J Clin Pathol 2009;131:166-71.

15. Kang SY, Suh JT, Lee HJ, Yoon HJ, Lee WI. Clinical usefulness of free light chain concentration as a tumor marker in multiple myeloma. Ann Hematol 2005;84: 588-93.

16. Piehler AP, Gulbrandsen N, Kierulf P, Urdal P. Quantitation of serum free light chains in combination with protein electrophoresis and clinical information for diagnosing multiple myeloma in a general hospital population. Clin Chem 2008;54:1823-30.

17. Carbone PP, Kellerhouse LE, Gehan EA. Plasmacytic myeloma. A study of the relationship of survival to various clinical manifestations and anomalous protein type in 112 patients. Am J Med 1967;42:937-48.

18. Durie BG, Salmon SE. A clinical staging system for multiple myeloma. Correlation of measured myeloma cell mass with presenting clinical features, response to treatment, and survival. Cancer 1975;36:842-54.

19. Yun JP, Suh C, Lee E, Chang JW, Yang WS, Park JS, et al. Comparison of serum B-2 microglobulin and 24 hour urinary creatinine clearance as a prognostic factor in multiple myeloma. J Korean Med Sci 2006;21:639-44.

20. Facon T, Abet-Loiseau H, Guillerm G, Moreau P, Genevieve $\mathrm{F}$, Zandecki $\mathrm{M}$, et al. Chromsome 13 abnormalities identified by FISH analysis and serum beta 2 microglobulin produce a powerful myeloma staging system for patients receiving high-dose therapy. Blood 2001;97: 1566-71.

21. Cuzick J, De Stavola BL, Cooper EH. Long-term prognostic value of serum B-2-microglobulin in myelomatosis. Br J Haematol 1990;75:506-10.

22. Bataille R, Greiner J, Sany J. Beta-2-microglobulin in myeloma: optimal use for staging, prognosis and treat- 
ment: a prospective study of 160 patients. Blood 1984; 63:468-76.

23. Abildgaard N, Bentzen SM, Nielsen JL, Heickendorff L. Serum markers of bone metabolism in multiple myeloma: prognostic value of the carboxy-terminal telopeptide of type I collagen (ICTP). Nordic Myeloma Study Group (NMSG). Br J Haematol 1997;96:103-10.

24. van Rhee F, Bolejack V, Hollmig K, Pineda-Roman M, Anaissie E, Epstein J, et al. High serum-free light chain levels and their rapid reduction in response to therapy define an aggressive multiple myeloma subtype with poor prognosis. Blood 2007;110:827-32.

25. Kyrtsonis MC, Vassilakopoulos TP, Kafasi N, Sachanas S, Tzenou T, Papadogiannis A, et al. Prognostic value of serum free light chain ratio at diagnosis in multiple myeloma. Br J Haematol 2007;137:240-3.

26. Dispenzieri A, Kyle R, Merlini G, Miguel JS, Ludwig H, Hajek R. International Myeloma Working Group guidelines for serum-free light chain analysis in multiple myeloma and related disorders. Leukemia 2009;23:215-24. 